\title{
Histidine Decarboxylase Activity in Fetal Intrauterine Growth-retarded Rats
}

\author{
MELINDA S. KWONG, THOMAS C. MOORE, CARLOS A. E. LEMMI, WILLIAM OH, \\ AND DONALD W. THIBEAULT ${ }^{(19)}$ \\ Divisions of Perinatal Medicine, Departments of Pediatrics and Surgery, Harbor General Hospital, UCLA School of \\ Medicine, Torrance, California, USA
}

\section{Extract}

Fetal intrauterine growth retardation was induced in nine rats at 17 days' gestation by ligating the blood supply to one of the uterine horns. The $\mathbf{2 7}$ fetuses from the uterine vessel ligated side were the intrauterine growth retarded fetuses (IUGR) and the 37 fetuses from the nonligated side were controls. The mean weight of the IUGR fetuses was $3.4 \pm 0.3 \mathrm{~g}$ which was significantly smaller $(P<$ 0.005 ) than the mean weight of the control fetuses, $4.0 \pm 0.3 \mathrm{~g}$.

Whole body histidine decarboxylase (HDC) activity was assayed by a radioisotope method. The HDC activity per $\mathrm{g}$ tissue was not correlated to body weight in the control fetuses. This is in contrast to the IUGR fetuses in which the HDC per g tissue was significantly and inversely related to body weight $(r-0.48, P<0.001)$.

\section{Speculation}

Increased histidine decarboxylase activity and histamine formation are generally associated with increased growth. Fetal rat intrauterine growth retardation was correlated with increased HDC activity. This suggests that the growth-retarded fetuses were attempting to maintain growth by increasing HDC activity and histamine formation.

Kahlson et al. (2) in 1958 described an increase in excretion of histamine in the urine of pregnant rats during the last third of gestation beginning on day 15, an peaking 1-2 days before birth of the young. The 15th day marks the onset of rapid growth of the rat fetus. Kahlson et al. (3) also found that there was a relationship between urinary histamine excretion and the number of fetuses; the greater the number of fetuses, the greater the urinary histamine excretion. They also showed that the increased formation of histamine during the last third of pregnancy comes from the fetuses and not the placentas (3).

All fetal rat tissues are potent producers of histamine, with the liver accounting for $80 \%$ of histamine formed by the fetus $(4,5)$. Histamine is formed in the rat from L-histidine by the action of the enzyme HDC. During the period of rapid growth of the rat fetus, there is high liver histidine decarboxylase activity. On the day before term when the maternal excretion of histamine is decreasing, the HDC activity of the fetal liver has fallen to the low level found in the newborn. Within 2-3 days postnatally, the HDC activity of the liver regresses further to that level found in the adult animal (5).

Suppression of embryonic histamine formation by the administration of semicarbazide to the pregnant rat results in arrest of fetal growth and consequent fetal death (1). These data seem to suggest that histamine production is intimately related to growth in the rat fetus. Using the experimental model of Wigglesworth (16) for inducing intrauterine growth retardation, we measured histidine decarboxylase activity in growth-retarded fetuses and their littermate controls, the hypothesis being, would experimental growth retardation be associated with a decrease in histidine decarboxylase activity?

\section{MATERIAL AND METHODS}

Nine time-dated pregnant rats of the Sprague-Dawley strain were used for this experiment. At 17 days of gestation (duration of rats' pregnancy $=21$ days) a laparotomy was performed under ether anesthesia with sterile technique. The uterus was exposed. As shown in Figure 1, the rat uterus is composed of two uterine horns, each with its own utero-ovarian blood supply. A silk ligature was applied to the cervical end of the uterine vessels. The opposite uterine horn was left untouched and the fetuses located in this horn were used as controls. The uterus was returned to the abdominal cavity, the laparotomy wound was closed, and the pregnancy was allowed to continue. Antibiotics were not administered postoperatively. The fetuses were delivered at 21 days of gestation by cesarean section under ether inhalation anesthesia. Each fetus was weighed and immediately frozen by immersion in liquid nitrogen and kept at $-80^{\circ}$ until analysis.

Histidine decarboxylase activity was assayed by the ${ }^{14} \mathrm{C}$ radioisotope method of Schayer (15). This method involved the incubation of $\left[{ }^{14} \mathrm{C}\right]$ histidine with whole fetal rat homogenates, appropriate cofactors, and metabolic conditions in a Dubnoff metabolic shaker for a 3 -hr period. The $\left[{ }^{14} \mathrm{C}\right]$ histamine produced was extracted in butanol two times after the addition of cold histamine carrier and was then converted to benzene-sulfonyl $\left[{ }^{14} \mathrm{C}\right]$ histamine, which was purified by recrystallization over a period of 5 days. The radioactivity was corrected for tissue blank and background count. Recovery of benzene-sulfonyl histamine, which reflects the histidine decarboxylase activity in the tissue, was calculated and expressed as disintegrations per min per g tissue.

\section{RESULTS}

Nine rats and 63 fetuses were studied. Thirty-six fetuses were from the nonligated side and are termed controls. Twenty-seven fetuses were from the uterine vessel-ligated side and are termed IUGR. Dead fetuses were discarded. The mean weight of the IUGR fetuses was $3.4 \pm 0.3 \mathrm{~g}$, which was significantly smaller $(P$ $<0.005)$ than the mean weight of the control fetuses, $4.0 \pm 0.3 \mathrm{~g}$.

The HDC activity per $g$ of tissue of all the fetuses was linearly and significantly related to body weight $(r=0.47, P<0.005)$ with the HDC per g tissue increasing as body weight decreased (Fig. 2). However, as shown in Figure 3, the HDC per g tissue was not correlated to body weight in the control fetuses. That is, there was a variation of weights within the control group, but there was no corresponding change in HDC activity. This is contrasted with the 


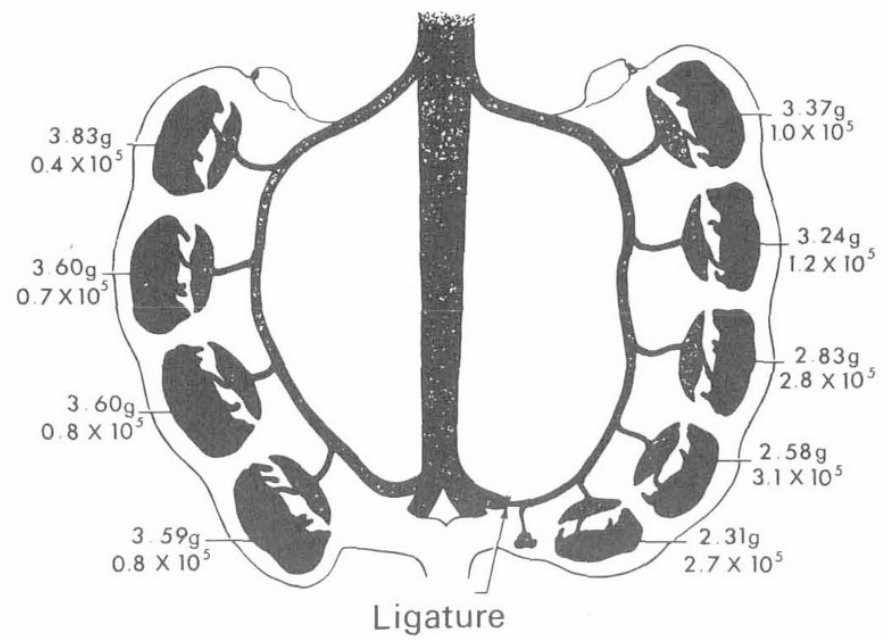

Fig. 1. Shown are the two uterine horns, each with its own utero-ovarian blood supply. A silk ligature is applied to the cervical end of the uterine artery. The opposite uterine horn was left untouched and the fetuses located in this horn were used as controls. Also shown is the birth weight and histidine decarboxylase activity per tissue in the fetuses of one experimental rat. The closer the fetal position to the site of the ligature, the greater the degree of growth retardation. The smaller growth-retarded rats have the greater histidine decarboxylase activity.

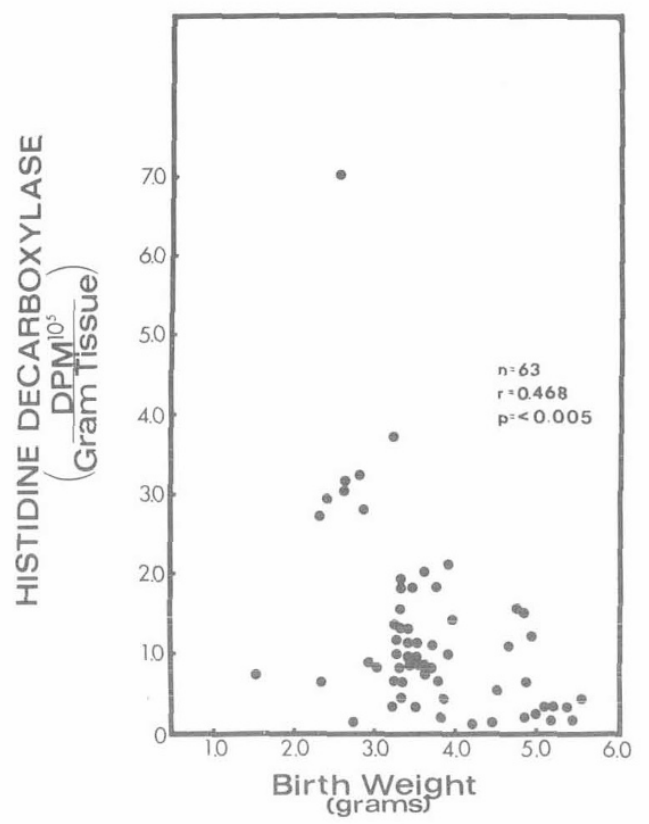

Fig. 2. As birth weight decreased, the histidine decarboxylase activity per body weight linearly and significantiy decreased $(r=0.48, P<0.001)$.

IUGR animals where the HDC per $g$ tissue was significantly and inversely related to body weight $(r=0.48, P<0.001)$.

Figure 1 shows the birth weight and HDC activity per g tissue in the fetuses of one experimental rat which is representative of all the rats studied. The birth weights and HDC activity of the control fetuses were relatively similar. In contrast, the IUGR fetuses show a difference in birth weight and HDC activity which is related to the position in the uterus and proximity to the uterine vessel ligature. The similarity of the HDC activity, despite decreasing size in the three IUGR animals closest to the uterine vessel ligature, suggests that in these fetuses, the limit of increase of HDC activity with growth retardation had been reached.

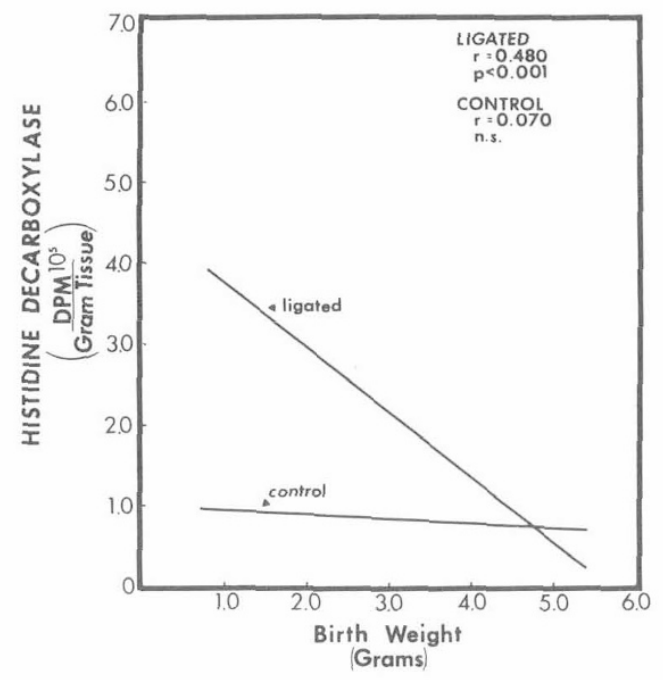

Fig. 3. The histidine decarboxylase activity per g body weight increased with decreasing birth weight in intrauterine growth-retarded fetuses from the uterine horn with the interrupted uterine blood supply. In control fetuses there appeared to be no relationship of histidine decarboxylase activity to birth weight.

\section{DISCUSSION}

The present study model readily produced intrauterine fetal growth retardation by reducing the blood supply to the maternal portion of the placenta. The exact mechanism by which growth retardation occurs is not clear. It is likely that the final common pathway is a reduction in the rate of supply of nutrient to the fetus, decreased removal of metabolic wastes, and therefore possible accumulation of toxic products and a decreased rate of oxygen and carbon dioxide exchange. This model has the advantage of producing a continuum of growth failure from minimal or none to severe (16).

In the present study, the HDC activity (HDC per g tissue) was unrelated to body weight in the control fetuses but was inversely related to body weight in the IUGR fetuses. This was an unanticipated finding since HDC activity in the rat is thought to be directly associated with growth (5). However, Schayer has shown in adult mice that HDC activity is increased with a variety of nonspecific stresses $(9,10)$, injection of epinephrine (10), and endotoxins $(8,10)$. He proposed $(11,14)$ that local histamine formation, increased through the induction of HDC, is capable of modulating microcirculatory blood flow by the opening of precapillary sphincters in response to local environmental changes. Our data show an increased HDC activity in growth-retarded fetuses which were possibly severely stressed secondary to placental vascular insufficiency. With tissue deprivation of nutrients and oxygen as occurred in the intrauterine growth-retarded fetuses, an increase of local tissue histamine could be beneficial by maximally dilating the vessels; this would require an increase in histidine decarboxylase activity.

\section{SUMMARY}

Fetal intrauterine growth retardation was induced in nine pregnant rats at 17 days' gestation by ligating the blood supply to one of the uterine horns. The animals were delivered by cesarean section at 21 days' gestation. Histidine decarboxylase activity per g body tissue was found to be significantly elevated in growth-retarded fetuses compared with control fetuses.

\section{REFERENCES AND NOTES}

1. Kahlson, G., and Rosengren, E.: Inhibition of histamine formation and some of its consequences. J. Physiol., 149: 66 (1959). 
2. Kahlson, G., Rosengren, E., and Westling, H.: Increased formation of histamine in the pregnant rat. J. Physiol., 143: 91 (1958).

3. Kahlson, G., Rosengren, E., Westling, H., and White, T.: The site of increased formation of histamine in the pregnant rat. J. Physiol., 144: 337 (1958).

4. Kahlson, G., Rosengren, E., and White, T.: Formation of histamine by the foetus in the rat and man. J. Physiol., 145: 30 (1960).

5. Kahlson, G., Rosengren, E., and White, T.: The formation of histamine in the rat foetus. J. Physiol., 151: 131 (1960).

6. Nitzan, M., and Groffman, H.: Glucose metabolism in experimental intrauterine growth retardation. Biol. Neonate, 17: 420 (1971).

7. Oh, W., D'Amodio, M. D., Yap, L. L., and Hohenauer, L.: Carbohydrate metabolism in experimental intrauterine growth retardation in rats. Amer. J. Obstet. Gyneco., 108: 415 (1970).

8. Reilly, M. A., and Schayer, R. W.: Further studies on the histidine-histamine relationship in vivo: Effects of endotoxin and of histidine decarboxylase inhibitors. J. Pharmacol., 34: 551 (1968).

9. Schayer, R. W.: Relationship of stress-induced histidine decarboxylase to circulatory homeostoses and shock. Science, 131: 226 (1960).

10. Schayer, R. W.: Relationship of induced histidine decarboxylase activity and histamine synthesis to shock from stress and from endotoxin. Amer. J. Physiol., 198: 1187 (1960).

11. Schayer, R. W.: Significance of induced synthesis of histamine in physiology and

Copyright (c) 1976 International Pediatric Research Foundation, Inc. pathology. Chemotherapia, 3: 128 (1961).

12. Schayer, R. W.: Evidence that induced histamine is an intrinsic regulator of the microcirculatory system. Amer. J. Physiol., 202: 66 (1962).

13. Schayer, R. W.: Induced synthesis of histamine, microcirculatory regulation and the mechanism of action of the adrenal glucocorticoid hormones. Progr. Allergy, 7: 187 (1963).

14. Schayer, R. W.: Histamine and autonomous responses of the microcirculation; relationship to glucocorticoid action. Ann. N. Y. Acad. Sci., 116:891 (1964).

15. Schayer, R. W : Enzymatic formation of histamine from histadine. In: M. Rocha e Silva: Handbook of Experimental Pharmacology. Part I. Histamine: Its Chemistry, Metabolism and Physiological and Pharmacological Actions, pp. 688-725 (Springer-Verlag, New York, 1966).

16. Wigglesworth, J. C.: Experimental growth retardation in the foetal rat. J. Pathol. Bacteriol., 88: 1 (1964).

17. Winick, M.: Cellular growth in intrauterine malnutrition. Pediat. Clin. N. Amer., 17: 69 (1970).

18. Dr. M. S. Kwong is a Fellow supported by the National Institutes of Health, Grant IF02 HD-53520-01

19. Requests for reprints should be addressed to: D. W. Thibeault, M.D., Department of Pediatrics, Harbor General Hospital, 1000 W. Carson St., Torrance, Calif. 90509 (USA).

20. Accepted for publication February 25, 1976.
Bacterial activity chronic granulomatous disease glucose-6-P dehydrogenase lability
glucose-6-P dehydrogenase Mediterranean variant

leukocytes

nitroblue tetrazolium

Printed in U.S.A.

\title{
Leukocyte Function and Characterization of Leukocyte Glucose-6-phosphate Dehydrogenase in Sicilian Mutants
}

\author{
GINO SCHILIRÒ, ${ }^{(25)}$ ANTONIO RUSSO, LUISA MAURO, GIUSEPPE PIZZARELLI, \\ AND SANTO MARINO \\ Departments of Paediatrics and Hygiene, University of Catania, Catania, Italy
}

\section{Extract}

Nine Sicilian children known to be deficient in glucose-6-phosphate dehydrogenase (G6PD) were studied to see if there were anomalies of bactericidal activity in peripheral blood phagocytes. The type of deficiency was established. The G6PD levels in the leukocyte were found to be $26 \%$ of the controls $(0.094 \pm 0.03$, normal controls $0.360 \pm 0.12$ ). The Michaelis constant for NADP and glucose-6-phosphate ( $\mathrm{G} 6 \mathrm{P}$ ) was lower than the control. Conversely, the utilization of the analogous 2-deoxyglucose-6-phosphate (2dG6P) and galactose-6-phosphate (Ga16P) was higher. The thermostability of the enzyme in the deficient subjects was lower and the $\mathrm{pH}$ optima ( 8 and 9.5 ) were different from the controls. An identical electrophoretic pattern was found in both normal and deficient subjects. The bactericidal activity in the deficient subjects was normal. There was no difference in the results of nitroblue tetrazolium (NBT) tests in either group.

\section{Speculation}

Although leukocyte G6PD was only one-quarter of the normal level, the phagocytic activity and the NBT test were normal in all subjects studied. It is not clear how such low levels of enzyme allow normal function. Perhaps further investigation under simulated intracellular conditions could give more reliable information about the enzyme activity.

During bactericidal activity phagocytes of peripheral blood utilize aerobic glycolysis with activation of hexosomonophosphate shunt (HMPS). The first step of HMPS is the breakdown of glucose-6-phosphate by G6PD which causes the reduction of NADP to NADPH. In the absence of G6PD the shunt is not activated and the bactericidal activity of phagocytes is blocked. In fact, Caucasians have been reported with absence of leukocyte G6PD associated with recurrent bacterial and fungal infections with a clinical picture similar to that of chronic granulomatous disease (CGD) $(1,5,7)$. Normal bactericidal activity has been found in Caucasians with leukocyte G6PD rate ranging from $20 \%$ to $50 \%$ of normal value $(2,5)$. In all of these cases, G6PD has not been characterized.

We examined Sicilian boys with erythrocyte G6PD deficiency to see if there were anomalies of bactericidal activity in peripheral blood phagocytes. The type of deficiency was established by studying some kinetic and biophysical characteristics of their leukocytic G6PD. 